\title{
Talk between Dussel and Forner-Betancourt: dialogue between philosophical knowledge, interculturality and indigenous school education
}

\section{Conversa entre Dussel e Forner-Betancourt: diálogo entre os saberes filosóficos, a interculturalidade e a educação escolar indígena}

\section{Hablar entre Dussel y Forner-Betancourt: diálogo entre conocimiento filosófico, interculturalidad y educación escolar indígena}

\author{
Henrique Moraes Júnior ${ }^{1}$ iD, Ivanilde Apoluceno de Oliveira ${ }^{1}$ iD \\ ${ }^{1}$ Universidade do Estado do Pará, Belém, Pará, Brasil. \\ Autor correspondente: \\ Ivanilde Apoluceno de Oliveira \\ Email: nildeapoluceno@uol.com.br \\ Como citar: Moraes Júnior, H., \& Oliveira, I. A. (2021). Talk between Dussel and Forner-Betancourt: dialogue between \\ philosophical knowledge, interculturality and indigenous school education. Revista Tempos e Espaços em Educação, \\ 14(33), e15642. http://dx.doi.org/10.20952/revtee.v14i33.15642
}

\begin{abstract}
Summary The article focuses on Enrique Dussel's Philosophy of Liberation, with the aim of reflecting on the articulation between modernity, the Eurocentric paradigm and the world paradigm. In this sense, the article develops the discussion on rationality and irrationality of modernity (myth of modernity) and its transmodernity (overcoming), as it is directly related to the question of the negative dialectical method with the negation of otherness - of indigenous populations - in philosophical systems. Eurocentric totality and points out the analytical movement as overcoming, expanding and liberating the negative dialectical method. It also outlines the intercultural philosophy of Rául Fornet-Betancourt, which aims at a symmetrical dialogue between philosophical knowledge. It is inferred, from the Liberation of the Other as Alterity and Interculturality, the concrete existence of a dialogical relationship between philosophical knowledge, enabling greater cosmological, philosophical and educational enrichment, as well as the teaching of intercultural philosophy in indigenous schools. In this study, the bibliographic review is the methodological strategy used.
\end{abstract}

Keywords: Dialogue. Dussel. Fornet-Betancourt. Indigenous education.

\section{RESUMO}

O artigo tematiza a Filosofia da Libertação de Enrique Dussel, com o objetivo de refletir sobre a articulação entre modernidade, paradigma eurocêntrico e paradigma mundial. Nesse sentido, o 
artigo desenvolve a discussão sobre racionalidade e irracionalidade da modernidade (mito da modernidade) e a sua transmodernidade (superação), pois guarda relação direta com a questão do método dialético com negação da alteridade - das populações indígenas - nos sistemas filosóficos de totalidade eurocêntrica e aponta o movimento analético como superação, ampliação e libertação do método dialético negativo. Esboça, também, a filosofia intercultural de Rául FornetBetancourt, que visa o diálogo simétrico entre os saberes filosóficos. Infere-se, a partir da Libertação do Outro como Alteridade e a Interculturalidade a existência concreta de relação dialógica entre os saberes filosóficos, possibilitando maior enriquecimento cosmológicos, filosóficos e educacionais, bem como o ensino de filosofia intercultural em escolas indígenas. Neste estudo a revisão bibliográfica é a estratégia metodológica utilizada.

Palavras-chave: Diálogo. Dussel. Educação indígena. Fornet-Betancourt.

\section{RESUMEN}

El artículo se centra en la Filosofía de la Liberación de Enrique Dussel, con el objetivo de reflexionar sobre la articulación entre modernidad, paradigma eurocéntrico y paradigma mundial. En este sentido, el artículo desarrolla la discusión sobre la racionalidad e irracionalidad de la modernidad (mito de la modernidad) y su transmodernidad (superación), porque se relaciona directamente con la cuestión del método dialéctico con la negación de la alteridad -de las poblaciones indígenas-en los sistemas filosóficos de la totalidad eurocéntrica y señala al movimiento analético como superador, expansivo y liberador del método dialéctico negativo. También esboza la filosofía intercultural de Rául Fornet-Betancourt, que apunta a un diálogo simétrico entre saberes filosóficos. Se infiere, de la Liberación del Otro como Alteridad e Interculturalidad, la existencia concreta de una relación dialógica entre saberes filosóficos, posibilitando un mayor enriquecimiento cosmológico, filosófico y educativo, así como la enseñanza de la filosofía intercultural en las escuelas indígenas. En este estudio, la revisión bibliográfica es la estrategia metodológica utilizada.

Palabras clave: Diálogo. Dussel. Educación indígena. Fornet-Betancourt.

\section{INTRODUÇÃO}

O paradigma eurocêntrico da modernidade estabeleceu a suposta superioridade cultural e racional da Europa, que, ao ser criticado pela proposta filosófica de Dussel (2007; 2005), foi deslocado do centro do sistema-mundo com o processo de "descoberta", conquista e colonização da América, ou seja, a centralidade e suposta superioridade foram colocados em perspectiva e historicizados.

A racionalidade moderna foi responsável pelo processo civilizador, legitimando a cultura europeia, como superior e desenvolvida, e exerceu uma irracionalidade violenta sobre o Outro, ao considerá-lo culpado por sua suposta imaturidade civilizatória - consistindo isso segundo Dussel (1993), no mito da modernidade.

Diante disso, como superar este mito da modernidade? Na proposta filosófica de Dussel (1974a; 1974b) tal processo de superação ocorre necessariamente pela negação do míticoirracional da modernidade, que implica em outro processo filosófico: a incorporação do Outro sem a submissão à racionalidade moderna, isto é, sem a submissão colonial europeia.

Se o horizonte filosófico de Dussel é contribuir para a superação da modernidade, de que maneira é observada por ele a negação da alteridade no método dialético?

Conforme Dussel (1974a), a magnitude do método dialético ocidental (leia-se, europeu) foi alcançada na obra de Hegel, cuja leitura do método buscava investigar (princípio, meio e fim) o desenvolvimento do espírito absoluto enquanto infinito e totalidade. Todavia, neste processo de investigação, houve, ao mesmo tempo, a incorporação e negação do Outro enquanto ser - a existência autônoma das populações indígenas - no "o mesmo", ocorrendo, por isso, a interdição da sua cotidianidade, da individualidade e da corporalidade. 
Embora Dussel (1974b) ressalte que na crítica de Heidegger a Hegel havia a intenção de superar seu sistema filosófico, por meio da reiteração do Dasein (ser-ai) no cotidiano, o que aconteceu, na verdade, foi a atualização do método dialético que compreendeu que todo ente está no ser "o mesmo", reproduzindo a mesma negação do Outro, ao estabelecer a existência do ente de modo independente.

El método dialéctico u ontológico llega hasta el horizonte del mundo, la comprensióndel ser, o la identidad del concepto en y para-sí como idea absoluta en Hegel: «el pensar que piensa el pensamiento». La ontología de la identidad o de la totalidad piensa o incluye al otro (o lo declara intrascendente para el pensar filosófico mismo) [...] El método dialéctico es el camino que la totalidad realiza em ella misma; desde los entes al fundamento y desde el fundamento a los entes (Dussel, 1974b, p. 175 e 182).

Dussel (1974b), então, propõe o método analético como superação da negação do Outro como Outro em ser quando legitima seu direito em ser na totalidade tendo reconhecimento como Outro indígena e seu modo de ser ontológico e filosófico no qual a condição primeira do universo é a humanidade (e não a animalidade), não se reduzindo ao "o mesmo", mas exercendo seu direito em ser.

El pasaje de la totalidad ontológica al otro como otro es analéctica, discurso negativo desde la totalidad, porque se piensa la imposibilidad de pensar al otro positivamente desde la misma totalidad; discurso positivo de la totalidad, cuando piensa la posibilidad de interpretar la revelación del otro desde el outro (Dussel, 1974b, p. 183).

Considera ainda Dussel (2007) que a aceitação do Outro como Outro significa uma opção ética, por envolver uma escolha e um compromisso moral. A filosofia na perspectiva analética e libertadora caminha por meio do reconhecimento da palavra do outro.

Raúl Fornet-Betancourt (2006) propõe a libertação do Outro negado e excluído pelo fechamento eurocêntrico do filosofar criado pelo não reconhecimento e dialogo com Outras tradições culturais e filosóficas, que se dá pela Filosofia Intercultural, buscando transformar essas condições com outras experiências contextuais (culturais) filosóficas plurais no compartilhamento enriquecedor comunitário e o reconhecimento do Outro como condição de relação e diálogos simétricos, isto é, sem gerar centro e periferia assimétricos, mas igualdade com o outro.

Essa relação de proximidade entre Dussel e Fornet-Betancourt nos remete à discussão sobre libertação e interculturalidade na filosofia como fundamental em tempos nos quais os direitos indígenas são revogados e a cultura indígena é cada vez mais subtraída da identidade nacional e o respeito aos seus saberes filosóficos diante do hegemônico são excluídos.

Porém com luta, resistência e morte o seu grito de libertação tem criado eco e transformação. Infere-se que a libertação da alteridade fundada na revelação do Outro como Outro e o diálogo igualitário com o Outro sem gerar opressor e oprimido, mas a possibilidade concreta da relação dialógica horizontal entre a filosofia indígena em pé de equivalência com a filosofia ocidental europeia.

Viabiliza um quefazer filosófico plural e enriquecedor da humanidade ao quebrar a cosmovisão do mundo unilateral, apontando para uma perspectiva filosófica pluri e interrelacional.

Neste artigo o objetivo é analisar o diálogo entre a filosofia intercultural de Raúl FornetBetancourt e a filosofia da libertação de Enrique Dussel e o reconhecimento da filosofia e da educação escolar indígena

Consiste em uma pesquisa bibliográfica, cujas principais fontes são Enrique Dussel e Raul Fornet-Betancourt, além de autores que tratam da educação. 
O artigo está organizado nas seguintes seções: 1 - Introdução; 2 - Paradigma da Modernidade: o olhar dusseliano; 3 - Racionalidade e Mito da modernidade: a crítica Dusseliana; 4 - Filosofia da Libertação de Enrique Dussel: crítica à razão dialética de Heidegger e Hegel; 5 Filosofia Intercultural Betancourteana; 6 - Diálogo entre a Filosofia intercultural e a da Libertação: possibilidade do reconhecimento da filosofia e educação indígena e 7 - Considerações finais.

\section{PARADIGMAS DA MODERNIDADE: O OLHAR DUSSELIANO}

Segundo Dussel (2007, p. 51) no livro: "Ética da Libertação na idade da globalização e da exclusão", "há dois paradigmas da modernidade", o europeu de horizonte hermenêutico eurocêntrico que propõe o "fenômeno da modernidade é exclusivamente europeu; que vai se desenvolvendo desde a Idade Média e se difunde posteriormente em todo o mundo.

"Este se autolegitima como único, verdadeiro, universal, possível, objetivo, poder, ser, saber e ter", mas que para Dussel (1993, p. 17; 2007, p.51) não passa de uma "falácia desenvolvimentista", no que corresponde as suas "características excepcionais internas" de superioridade cultural em relação às demais culturas, se configurando como mito da modernidade, cujo discurso consiste em uma "'saída' da imaturidade por um esforço da razão como processo crítico, que proporciona à humanidade um novo desenvolvimento de ser humano" (Dussel 2005, p. 28).

Assim, a história universal europeia ocidental teria características de modernidade chegando ao seu ápice por fatores históricos exclusivos, perpassando da "Itália do Renascimento até a Alemanha da Reforma e da Ilustração, para a França da Revolução Francesa" (Dussel 2007, p. 52).

Esta visão eurocêntrica indica fenômenos intra-europeus da modernidade, na medida em que o seu desenvolvimento necessita unicamente da Europa para explicar o processo, ou seja, a Europa moderna nada aprende com outros mundos culturais "tem um princípio em si mesma e é sua plena 'realização'” (Dussel 1993, p. 21).

Para Dussel (2007, p. 51), "filosoficamente, ninguém como Hegel expõe esta tese da modernidade".

O Espírito germânico é o espírito do Novo Mundo, cujo fim é a realização da Verdade absoluta (der absoluten Wahrheit), como autodeterminação (Selbstbestimmung) infinita da liberdade, que tem por conteúdo sua própria forma absoluta (die ihre absolute Form selbst).

Explica Dussel (2007, p. 52) que a modernidade europeia:

não é um sistema independente autopoiético, autorreferente, mas é uma "parte" do "sistemamundo": seu centro. A modernidade, então, é um fenômeno que vai se mundializando; começa pela constituição simultânea da Espanha com referência a sua "periferia" (a primeira de todas. propriamente falando, a Ameríndia: o Caribe, o México e o Peru). Simultaneamente, a Europa (com uma diacronia que tem um antecedente pré-moderno: as cidades italianas renascentistas e Portugal) irá se transformando no "centro" (com um poder super hegemônico que, da Espanha, passa para Holanda, Inglaterra e França...) sobre uma "periferia" crescente (Ameríndia, Brasil e as costas africanas de escravos, Polônia, no século XVI; afiançamento de América Latina, América do Norte, o Caribe, as costas da África e da Ásia e a Europa oriental, no século XVII". o Império Otomano, Rússia, alguns reinos da Índia, Sudeste Asiático e primeira penetração na África continental, até à primeira metade do século XIX). Então a modernidade seria, para este paradigma mundial, um fenômeno próprio do "sistema" com "centro e periferia".

Sobre o paradigma mundial da modernidade Dussel (2007, p. 635) defende a tese de que:

O 'paradigma mundial da modernidade', que propõe que a Europa, sem ter uma superioridade própria (e se a teve, em algum aspecto particular, não foi a causa da modernidade), pelo 
descobrimento da Ameríndia em 1492 teve um horizonte geopolítico, econômico, político e cultural que lhe deu uma vantagem comparativa (especificamente sobre o mundo otomanomuçulmano e chinês), a partir de onde acumulou, durante os séculos XVI e XVII, potencial suficiente para superar, a partir do século XVIII, agora sim, as altas culturas asiáticas. É uma miragem eurocêntrica 'antecipar' para a Idade Média europeia a evidente superioridade (especialmente tecnológica) sobre as outras culturas periféricas conseguida no século XVIII. A Europa certamente teve superioridade sobre a Ameríndia já no século XV (mas não sobre o mundo otomano-muçulmano, a Índia e, sobretudo, a China).

Dussel (2007, p. 52), então, defende que a História como centralidade não começa na Europa desde sempre "não é fruto só da superioridade interna acumulada na Idade Média europeia sobre as outras culturas". Porém se inicia com os sistemas Interregionais do Egipcio-mesopotâmico (desde o IV milênio a.C.); Indo-europeu (desde o século XX a.C.); Asiático-afro-mediterrâneo (desde o século IV a.C.) e Sistema-mundo (desde 1492 dC), ou seja, antes da conquista da América, a Europa era periferia do sistema interregional Asiático-afro-mediterrâneo do mundo Otomano-Mulçumano.

O velho continente deixa de ser periferia com a colonização das terras "descobertas", isto é, o sistema-mundo nasce da conquista da América rumo ao centro por exploração de riquezas, corporal, espiritual, conhecimento, experiência, tecnologia e passando a ampliar seu poder de rivalidade com os sistemas interregional Asiático afro-mediterrâneo, o mundo otomanomulçumano, índia e China.

Assim, a Europa torna-se centro hegemônico se mundializando não por sua suposta superioridade em si e por si internamente cultural em relação a outras culturas, porém pelos movimentos de acúmulo de riquezas das colônias e a influência cultural de outras culturas asiáticas, mediterrâneo e entre outras.

\section{RACIONALIDADE E MITO DA MODERNIDADE: A CRÍTICA DUSSELIANA}

Na visão de Dussel (2005) no artigo: "Europa, modernidade e eurocentrismo", a inclusão no centro da modernidade racional é a saída do ser humano da imaturidade para um novo desenvolvimento. Entretanto, exerce a irracionalidade de práxis violenta sobre o Outro, sendo considerado como necessário, quer dizer, desde a "descoberta" da América, a Europa vem às outras culturas, mundos e indivíduos como Outro (diferente), mas objetificados, nadificados, bárbaros, incultos, selvagens e periféricos.

Legitima-se, desta forma, o processo colonizador-civilizador da modernidade por sua suposta superioridade cultural, epistemológica, ontológica e política que os obriga a desenvolverem os mais primitivos (os não-modernos; o não-ser).

Elucida Dussel (2005, p. 111-112) que no Mito da Modernidade:

1. A civilização moderna autodescreve-se como mais desenvolvida e superior (o que significa sustentar inconscientemente uma posição eurocêntrica).

2. A superioridade obriga a desenvolver os mais primitivos, bárbaros, rudes, como exigência moral.

3. O caminho de tal processo educativo de desenvolvimento deve ser aquele seguido pela Europa (é, de fato, um desenvolvimento unilinear e à europeia o que determina, novamente de modo inconsciente, a "falácia desenvolvimentista").

4. Como o bárbaro se opõe ao processo civilizador, a práxis moderna deve exercer em último caso a violência, se necessário for, para destruir os obstáculos dessa modernização (a guerra justa colonial).

5. Esta dominação produz vítimas (de muitas e variadas maneiras), violência que é interpretada como um ato inevitável, e com o sentido quase-ritual de sacrifício; o herói civilizador reveste a suas próprias vítimas da condição de serem holocaustos de um sacrifício salvador (o índio colonizado, o escravo africano, a mulher, a destruição ecológica, etc.). 
6. Para o moderno, o bárbaro tem uma "culpa" (por opor-se ao processo civilizador) que permite à "Modernidade" apresentar-se não apenas como inocente, mas como "emancipadora" dessa "culpa" de suas próprias vítimas.

7. Por último, e pelo caráter "civilizatório" da "Modernidade", interpretam-se como inevitáveis os sofrimentos ou sacrifícios (os custos) da "modernização" dos outros povos "atrasados" (imaturos), das outras raças escravizáveis, do outro sexo por ser frágil, etc.

Desta forma, para Dussel (2005), o Mito da modernidade negou aos Outros (ser) e suas totalidades culturais (pluralidades), por considerá-los como inferiores, atrasados, débeis, bárbaros, selvagens e não-seres. Isto é, sendo considerados culpados de sua vitimação, imaturidade e o vitimador moderno inocente ao vitimá-lo, legitimando a violência colonizadora e o sofrimento "necessário" ou "inevitável" para o Outro ser civilizado e emancipado pelo ser europeu de "purismo" cultural.

Como transcender a Modernidade? Afirma Dussel (2005, p. 31) que:

Apenas quando se nega o mito civilizatório e da inocência da violência moderna se reconhece a injustiça da práxis sacrificial fora da Europa (e mesmo na própria Europa) e, então, pode-se igualmente superar a limitação essencial da "razão emancipadora". Supera-se a razão emancipadora como "razão libertadora" quando se descobre o "eurocentrismo" da razão ilustrada, quando se define a "falácia desenvolvimentista" do processo de modernização hegemônico. Isto é possível, mesmo para a razão da llustração, quando eticamente se descobre a dignidade do Outro (da outra cultura, do outro sexo e gênero, etc.); quando se declara inocente a vítima pela afirmação de sua Alteridade como Identidade na Exterioridade como pessoas que foram negadas pela Modernidade. Desta maneira, a razão moderna é transcendida (mas não como negação da razão enquanto tal, e sim da razão eurocêntrica, violenta, desenvolvimentista, hegemônica). Trata-se de uma "Transmodernidade" como projeto mundial de libertação em que a Alteridade, que era coessencial à Modernidade, igualmente se realize. A "realização" não se efetua na passagem da potência da Modernidade à atualidade dessa Modernidade européia. A "realização" seria agora a passagem transcendente, na qual a Modernidade e sua Alteridade negada (as vítimas) se co-realizariam por mútua fecundidade criadora. O projeto transmoderno é uma co-realização do impossível para a Modernidade; ou seja, é co-realização de solidariedade, que chamamos de analéptica, de: Centro/Periferia, Mulher/Homem, diversas raças, diversas etnias, diversas classes, Humanidade/Terra, Cultura Ocidental/Culturas do mundo periférico ex-colonial, etc.; não por pura negação, mas por incorporaçãopartindo da Alteridade.

Nesta perspectiva, o transmoderno ou a transmodernidade consiste no real emancipador da racionalidade moderna e do Outro negado em sua exterioridade-alteridade da modernidade em negação do caráter mítico-irracional em superação ou transcendido na libertação se mundializando na alteridade negada incluindo a "modernidade/alteridade". Ou seja, a posição e relação ética com o Outro como Outro (plural) não como o visto mesmo (uno) europeu, mas o Outro (distinto) com igualdades ontológicas, epistemologias, políticas, filosóficas e culturais.

\section{FILOSOFIA DA LIBERTAÇÃO DE ENRIQUE DUSSEL: CRÍTICA À RAZÃO DIALÉTICA DE HEIDEGGER E HEGEL}

Dussel interpreta a filosofia moderna eurocêntrica dominante alinhada ao sistema-mundo (paradigma mundial), sendo a dialética o método filosófico, que fundamenta um sistema filosófico uno e de totalidade, cujos principais referenciais são Hegel e Heidegger, por meio do qual há a negação da alteridade ou exterioridade, ou seja, da diversidade do Outro como Outro.

No livro "Método para uma Filosofia da Libertação", Dussel (1974a, p. 17) afirma que a dialética é um método oriundo do grego metáhó-dos, que significa "um caminho, um movimento 
radical e introdutório àquilo que as coisas são. O método dialético é o próprio início". Explica, ainda, que Hegel no livro "Fenomenologia do Espírito", em tempos da maturidade, apresenta a dialética como método e caminho ou o meio, fim e princípio do processo absoluto do conhecer real que o "ser é a síntese do sujeito e do objeto, na qual o sujeito e o objeto perdem sua oposição" (Dussel, 1974a, p. 73).

Destaca Dussel que em primeiro nível apresentam-se as oposições de sujeito-objeto e no segundo nível as oposições são superadas no abarcamento da unidade. A superior síntese dialética é o conhecimento e de si, único (mesmo), exclusivo, infinito, universal, totalidade, absoluto, filosófico e que se mundializa. Além disso, nada há de se conhecer, nem pensamento, existência, tudo é esta unidade, sistema e absoluto:

Não há nada, então, que exerça a função de uma exterioridade à própria consciência porque 'o conceito e o objeto, a medida (fundamento) e aquilo a que se há de aplicar estão presentes em (in) a própria consciência'. Definitivamente, a consciência designa dentro de si o em si ou o verdadeiro como o que, por outro lado, é a medida que ela mesma estabelece para medir seu saber (Dussel, 1974a, p. 87).

Porém, ressalta Dussel (1974a), que no bojo de realização do sistema dialético está à negação ou exclusão da pluralidade e diversidade da alteridade ou exterioridade do Outro como Outro em ser; em sua corporalidade, individualidade e cotidianidade. Considera que a "dialética começa então por negar a cotidianidade, não porém para implantar o cotidiano num âmbito transcendente ou além, mas para alcançar involutivamente uma totalidade aquém" (Dussel, 1974a, p. 84, 73 e 78).

Acrescenta que o outro torna-se o mesmo (incorporação) do "todo como unidade" ou é eliminado do sistema sua legitimidade como outro em ser; um verdadeiro senhor (ser é) e escravo (ser não é), o escravo não é por si só, porém apenas é no senhor, isto é, "Hegel pensa que o homem pode abarcar o finito a partir do infinito, alcançar, então o todo sem exterioridade." Em Heidegger a dialética apresenta-se o ser, em não involução como em Hegel, que a dialética nega o cotidiano ao absoluto, espírito, único (mesmo), universal, sem alteridade e metafísico, porém reafirma o cotidiano (tempo) que está o ser-aí (Dasein) concreto com o mundo como início possível.

Este nível tinha sido deixado de lado pela modernidade, uma vez que ela partia da fatícidade (factum), mas em direção involutiva, intra consciencial. Heidegger, em troca, propõe agora partir da cotidianidade permanecendo nela: a direção se inverte e, da experiência em sentido hegeliano (enquanto movimento dialético da consciência para a consciência e nela pelo descobrimento de um novo objeto) passa-se agora à tematização da própria experiência natural como mera cotidianidade, onde já está dada a totalidade do ser do homem: não há involução, mas reflexão sobre a própria transcendência (Dussel, 1974a, p. 169-170).

Na visão de Dussel (1974a, p. 171), o movimento dialético heideggeriano recoloca o ser no cotidiano, porém "Dasein, para Heidegger, não é todo ente, mas de maneira privilegiada somente aquele ente ao qual o ser se manifesta, somente aquele que descobre o ser. Explica, ainda, que:

Todo o livro Ser e Tempo é uma obra dialética. Desde a pergunta inicial do [...] o método é dialético, mas parte, diferentemente de Hegel, não do absoluto antes da criação e como ser indeterminado ou conceito em si, mas do Dasein, o ente que é aí, mas um, mas inevitavelmente um homem, 'em cada caso eu mesmo'. O ponto de partida não é o todo, mas o, por definição, intotal ou intotalizável: o homem, 'enquanto é um ente que é, jamais alcançou sua totalidade (seine Gaenze nie erreicht)' (Dussel, 1974a, p. 171). 
O movimento dialético, então, tem sua base última qualitativamente no ser ontológico, e ente, aquém, ôntico, isto é, de intotal ou intotalizável para total ou totalizável e a totalização limite como ser (ente) único (mesmo), absoluto e privilegiado como em Hegel, sem diálogo com o outro (ou entre não-totalizados). Porém incorpora, negando ou eliminando seu direito de ser outro na totalização dialética realizada isoladamente e sem dialogo.

Assim é 'todo ente'; a 'alma', que constitui o ser do homem, descobre, em seus modos de ser, [...] e [...], todo ente naquilo que ele é e como ele é, pois descobre sempre todo ente em seu ser" (HEIDEGGER 2005, p. 41), ou seja, todo ente é no ser ou o ser é o ente, para o além disso, não existe outro ou ser, apenas como ente, mas não como ser - como em Hegel no senhor e escravo.

Para Dussel (1974a, p. 215), "toda dialética, porém, e é mais grave, tem como fundamento a identidade do ser e a totalidade, isto é, o movimento dialético é o desenvolvimento de 'o mesmo' (único)", que incorpora, elimina ou nega o Outro como Outro em ser, mas visto como o mesmo sem diálogo com o outro, porém em si mesmo ou entre os mesmos no monólogo, ou seja, a dialética negativa do "o mesmo" enquanto falsa. Reconhece a alteridade em ser, critica o ser da totalidade do sistema-mundo eurocêntrico hegemônico da modernidade, apontando a analética, que se constitui em momento "crítico e superação do método dialético negativo, não o nega, assim como a dialética não nega a ciência, apenas o assume, o completa, lhe dá seu justo e real valor." (Dussel, 1995, p. 187). Ele apresenta cinco movimentos do método analético:

[...] en primer lugar, el discurso filosófico parte de la cotidianidad óntica y se dirige dialéctica y ontológicamente hacia el fundamento. En segundo lugar, demuestra científicamente (epistemática, apo-dícticamente) los entes como posibilidades existenciales. Es la filosofía como ciencia, relación fundante de lo ontológico sobre lo óntico. Entercer lugar, entre los entes hay uno que es irreductible a una deducción o demostración a partir del fundamento: el "rostro» óntico del otro que en su visibilidad permanece presente como trans-ontológico, metafísico, ético. El pasaje de la totalidad ontológica al otro como otro es analéctica, discurso negativo desde la totalidad, porque se piensa la imposibilidad de pensar al otro positivamente desde la misma totalidad; discurso positivo de la totalidad, cuando piensa la posibilidad de interpretar la revelación del otro desde el otro. Esa revelación del otro, es un cuarto momento, porque la negatividad primera del outro há cuestionado el nivel ontológico que es ahora creado desde un nuevo ámbito. El discurso se hace ético y el nivel fundamental ontológico se descubre como no originario, como abierto desde lo ético, que se revela después (ordo cognoscendi a posteriori) como lo que era antes (el priusdel ordo realitatis). En quinto lugar, el mismo nível óntico de las posibilidades queda juzgado y relanzado desde un fundamento éticamente establecido, y estas posibilidades como práxis analéctica transpasan el orden ontológico y se avanzan como «servicio» en la justicia (Dussel, 1974b, p.183).

A analética, então, não nega ou exclui a dialética negativa, mas sua continuidade de complemento, amplitude, alargamento e continuidade positiva.

Dussel (1974b) pelo método analético visa superar a negação do Outro como Outro, reconhecendo-o como ser ontológico e filosófico, não sendo reduzido ao "mesmo". Por meio de uma interpretação analética da história mostra-se a voz do outro que aflora da totalidade "civilizada", como ser negado em sua própria cultura valorada como "bárbara".

É nesta perspectiva que a América latina, de sua exterioridade bárbara aos olhos dos civilizados da Europa, lança sua voz e entra na história, com a sua filosofia, elaborada na própria práxis libertadora de povo oprimido. 


\section{FILOSOFIA INTERCULTURAL BETANCOURTEANA}

Raúl Fornet-Betancourt (2006) no livro "La interculturalidad a prueba" debate a possibilidade de uma filosofia intercultural, cujo objetivo é instruir o filósofo europeu a pensar além dos parâmetros eurocêntricos de filosofar, por não ensinar o diálogo intercultural na Filosofia.

Es posible que la forma en que el título de la ponencia anuncia el tema de la misma despierte la sospecha de certa presunción o de que se asume una actitud magistral poco modesta que pretende instruir al otro, en este caso, al filósofo europeo, sobre qué filosofia debe hacer hoy y cómo debe hacerla (Fornet-Betancourt, 2006, p. 62).

O autor problematiza como a filosofia é feita atualmente e destaca que o fazer filosófico é feito por meio de compromisso e experiência filosófica compartilhada em comunidade, na realidade histórica e alternativa de outros mundos possíveis construídos em movimentos sociais e culturais de resistência, sendo também contra a imposição de domínios filosóficos, financeiros e transnacionais, que contribuem ao aumento do empobrecimento da humanidade. Implica, ainda, em compreender a necessidade do compromisso filosófico com a história das pessoas que sofrem as consequências do progresso dominante.

De ahí que, considerando que tomar conciencia de la responsabilidad histórica es un acto que implica siempre haber superado lãs deformaciones del elitismo e individualismo, esta experiencia filosófica sea al mismo tiempo la experiencia de un filosofar em colectivo; de um filosofar consciente de que asumir el presente como tarea es compartir una tarea que es obra de muchos y muchas; y de que tiene, por tanto, que perfilarse como un filosofar que se hace en compañía y desde la compañía (Fornet-Betancourt, 2006, p.63).

A filosofia intercultural Iberoamericana de Fornet-Betancourt, então, propõe uma experiência filosófica contextual compartilhada, compreendendo ser uma ação coletiva que envolve uma humanidade plural, de diversas possibilidades de mundos e formas de realização, bem como o reconhecimento do Outro.

As principais características desta Filosofia Intercultural segundo o autor são: (a) a categoria "latino-americana" não contradiz ou limita o espírito intercultural deste modelo de filosofia por não ser pátria ou região particular, mas indicador contextual de experiência histórica com os outros; (b) sua orientação provisória no multiculturalismo como treinamento para sermos mais do que estamos com a diversidade do outro ao deixar as fronteiras para viver as diferenças e os contextos de experiência intercultural históricos dos Outros.

Salienta que a dimensão intercultural é fundamentada nas realidades contextuais da cultura (cross-cultural). "La experiencia es fuente de diversidad y, como tal, condición para la comunicación, el intercambio y el diálogo. La interculturalidad la presupone como el plural punto de partida de su propia dinámica de construir puentes entre lo diverso" (ForneT-Betancourt 2006, p.64).

A Filosofia Intercultural é variável ao responder a experiência contextual crítica ao lugar e temporalidade latino-americana que apresenta uma forma de governo centralizado e hierárquico não permitindo a igualdade na gestão da vida e convivência real. O seu contexto, na experiência histórica, é marcado por "desequilibrio político, social, cultural, religioso, económico e incluso lingüístico entre las 'familias' que la constituyen, y es así experiencia de conflicto e incomprensiones, de marginación y de negación, de opresión y de luchas por el reconocimiento" (Fornet-Betancourt 2006, p.64).

A filosofia intercultural, então, é expressão e veiculo de justiça dessas "famílias" ao direito a diversidade e igualdade negadas. Por isso, a filosofia intercultural latino-americana inicia o 
movimento de recuperação da diversidade contextual histórica, cujo eco libertador está nas vozes indígenas e africanas:

a fin de, desde esa experiencia de acompañamiento de la diversidad en activo, entrar en diálogo con las tradiciones que guían las luchas, fomentando además la comunicación entre el lasa sí como con las tradiciones de otros contextos, sobre todo en el nivel de sus estructuras cognitivas y referentes de valoración." (Fornet-Betancourt 2006, p.65).

Assim, a recuperação da diversidade e da comunicação silenciada, a filosofia intercultural tem projetado as lutas alternativas contra o empobrecimento do mundo e humanidade. Esta filosofia envolve a tarefa de combater o empobrecimento do mundo e da humanidade ao desenvolver filosofias contextuais das diversas tradições culturais, porque "[...] la cultura filosófica hegemónica en América no solo niegalas culturas originarias sino que incluso en su ámbito 'criollo' resulta en ajenante al frenar la creatividad y promover hábitos de imitación" (Fornet-Betancourt 2006, p.65).

Portanto, quebrar a hegemonia filosófica é o ponto central da filosofia intercultural, visando remundizar pluralmente a prática do diálogo com as histórias, vivências e diversidades culturais na América Latina.

A filosofia intercultural considera o diálogo como comunicativo, interativo e igualitário sem gerar centro e periferia, o que possibilita crescer interculturalmente o convívio, isto é, "[...] la filosofía intercultural iberoamericana es un proyecto de filosofar desde la pluralidad y para la convivencia solidaria en esa pluralidad." Além disso, "es filosofía para la construcción de un mundo mejor, habitado por una humanidad ecuménica que confie sas su universalidad en prácticas cotidianas de acogimiento." (Fornet-Betancourt 2006, p.66)

Desta forma, contribui em nível mundial para o diálogo intercultural e o reavivamento da filosofia na América Latina com a diversidade e pluralização da filosofia. Objetiva filosofar no mundo, criando formas de intercâmbio e interação do diverso em filosofia.

A filosofia intercultural, segundo Fornet-Betancourt (2006, p. 66) é a expressão da "vocación de universalidad contextualizada", por se caracterizar como um "[...] es fuerzo de redefinir los planes de estudio, lãs metodologias empleadas, los lugares y los sujetos de en señanza y transmisión, las prioridades en la política de publicación y, por supuesto, también de los criterios de acreditación y reconocimiento".

Essa filosofia desenvolve a reflexão sobre a prática, ou seja, visa transformar ao nível teórico, organizacional e institucional ao interesse do modelo, propósito e plano das atividades de transformação estrutural.

[...] Representa una práctica del filosofar que, como me parece que muestran los rasgos enunciados, se distingue por el esfuerzo de articularse como respuesta a la surgencias de nuestra época, pero desde una clara opción ética por la defensa del valor y de la dignidad de los pueblos que hoy son atropellados por los mecanismos de expansión del orden hegemónico. 0 sea que discierne las urgencias de nuestro tiempo 'desde abajo' y entiende que filosofar hoy a la altura de nuestro tiempo significa el compromiso de hacer causa común com los y las de 'abajo' para reorganizar el mundo con y desde sus necesidades, posibilidades y esperanzas (Fornet-Betancourt 2006, p.67)

O autor ainda destaca que a filosofia intercultural é motivada pelo desejo de compartilhar experiências e iniciar diálogo com outras culturas da filosofia, entre as quais a europeia. Por isso, convida ao diálogo como meio de mútua ajuda e convivência (Fornet-Betancourt, 2006). Porém, é preciso atentar ao fato de que a filosofia europeia é pouco aberta ao diálogo e interação com outras culturas de filosofia ou tradições. 
Na verdade, diríamos que esse "diálogo" fechado exclusivamente é feito com a linguagem, assuntos e lógica europeia causando uma exclusão (periferia/outro) e hegemonia (centro) como único caminho a ser seguido.

Fornet-Betancourt (2006, p. 67) questiona: o que tem incomodado a filosofia Europeia em equilibrar a relação com Outras filosofias? Qual é o incomodo do inevitável diálogo com o Outro? A regra ou a universalidade é a cultura dominante filosófica europeia fundamentada no "sucesso" colonialista, econômico, político e militar excluindo o contextual, o diálogo com o Outro e desnecessário, supérfluo, tolo e o outro não deveria existir. Explica o autor que:

La invitación al diálogo que proponemos, supone, enefecto, un cambio de actitud por parte de la filosofia europea; un cambio de espíritu que nos parece tanto más necesario cuanto que se trata de una invitación interpelante que viene de tradiciones que nunca ha reconocido como iguales (Fornet-Betancourt, 2006, p. 68).

Esse convite tem o objetivo de avaliar de forma crítica a teoria e o sistema de "excelência" civilizatória hegemônica e a possível dificuldade de aceitar o convite diz respeito provavelmente pelo receio de perda hegemônica sobre o Outro, embora seja necessário mudar o espírito para que o modelo da filosofia intercultural latino-americano seja capaz de fornece um serviço de primeira a filosofia europeia. Em outras palavras: ajudar a repensar, redescobrir e assumir reconhecimento de forma crítica, a nova perspectiva de recuperar a pluralidade filosófica intercultural cuja aplicabilidade é reconstruir a história com muitas outras históricas, tradições, vozes, alternativas, contingências e o contextual como condição ao diálogo a superar a hegemonia, a suposta universalidade metafísica e a marginalização (Fornet-Betancourt, 2006).

Esse diálogo perpassa pela relação entre filosofia e cultura.

Considerando por otra parte que la pluralización de la historia de la filosofía, sea em Europa o en cual quiero tra región del mundo, no es real si no va acompaña dade una vu el ta conse cuente a las tradiciones y culturas concretas de la gente en la variedad de sus muchos mundos de vida, que fundan de suyo la pluralidad filosófica, hay que ver también que estatarea de la pluralización implica, como su complemento necesario, la labor de replantear a la luz de la diversidad real contextual la forma en que la filosofía hegemónica ha concebido la relación entre 'filosofia' y 'cultura' (Fornet-Betancourt, 2006, p. 69).

Desta forma, o diálogo com a experiência intercultural filosófica é enriquecida na relação da filosofia-cultura, por isso, não é "a" filosofia que decide, mas as culturas e como resultado das culturas filosóficas vividas pelo povo.

Assim, há a urgência intercultural de renovação da filosofia europeia no mundo globalizado (neoliberal), que as utopias de convivência e diálogo entre culturas transformam-se em oportunidades de compartilhamento de experiências interculturais filosóficas de diversificar e contextualizar as organizações, instituições e perspectivas filosóficas intercultural de libertação dos sujeitos (periferia/Outro) do sistema hegemônico.

\section{DIÁLOGO ENTRE A FILOSOFIA INTERCULTURAL E A FILOSOFIA DA LIBERTAÇÃO: POSSIBILIDADE DO RECONHECIMENTO DA FILOSOFIA E DA EDUCAÇÃO ESCOLAR INDÍGENA}

Zimmermann (1986, p. 181) com base no pensamento de Dussel destaca que existe um ente - o ameríndio - que se recusar em ser de "o mesmo", ou seja, o 'rosto' ôntico do outro, grita no "clamor de justiça' de todos os oprimidos de todos os tempos e lugares".

Como obstáculo ou incomodo do Outro como Outro em ser (alteridade ou exterioridade), que "o mesmo" não foi capaz de reduzir a totalidade dialética inicial, se efetiva, como estratégia de dominação, a eliminação do outro em ser (o ameríndio), por meio do processo de colonização. 
Assim, a possibilidade que se apresenta é a luta e resistência, com o reconhecimento da pessoa ou condição humana do próprio índio e de seu modo de ser (ente), por meio do qual se efetiva a ruptura em relação à totalidade ontológica da dialética do "o mesmo", abrindo caminho para outras alteridades ou exterioridades e suas cargas representativas e interpretativas.

Mas quem são os sujeitos das populações indígenas? Jecupé (1998, p.14) apresenta a seguinte visão do indígena:

[...] é um ser humano que teceu e desenvolveu sua cultura e civilização intimamente ligado à natureza. A partir dela elaborou tecnologias, teologias, cosmologias, sociedades, que nasceram e se desenvolveram de experiências, vivências e interações com a floresta, cerrado, os rios, as montanhas e as respectivas vidas dos reinos animal, mineral e vegetal. Há inúmeras características e formas de relações do índio com a natureza, o que provocou o florescimento de muitas etnias, muitas variedades de línguas, muitos costumes.

Mediante este conceito, as autoras questionam: não haveria implicitamente na diversidade desses saberes tecnológicos, teológicos, cosmológicos e de sociedades um saber filosófico indígena de construção lógica sob a visão de mundo desses povos, ambientes, línguas e formas de viver?

Saberes que desocidentalizam e descolonizam a filosofia eurocêntrica, deslocando o olhar para outros logos não europeus e superando a ontologia ocidental de interpretar dicotomicamente a subjetividade e a objetividade; natureza e o ser humano, isto é, que "somos todos animais, sendo o espírito o elemento que diferencia humano e animais e o que sobrepõe os primeiros aos segundos." (Oliveira \& Albuquerque 2010, p. 202).

Conforme Oliveira \& Albuquerque (2010) para se entender o pensamento ameríndio, é preciso, compreender sua ontologia, na qual a condição primeira do universo é a humanidade (e não a animalidade) da qual surgem os demais conjuntos de seres.

Segundo Viveiros de Castro (2014, p. 244 e 255), estudioso do pensamento ameríndio: "se há uma noção virtualmente universal no pensamento ameríndio, é aquela de um estado originário de indiferenciação entre humanos e os animais". Deste modo, "a condição comum aos humanos e animais é a humanidade, não a animalidade", isto é, alude a refletir na existência de uma continuação (e não uma dicotomia) entre natureza e cultura.

Assim, na ontologia ameríndia, todos os seres naturais são sociais ao possuírem atributos humanos e características sociais. Fundada no animismo, admite a dimensão social das relações entre humanos e não humanos, diferentemente da ontologia ocidental, cujas relações sociais entre os sujeitos só podem existir no contexto da sociedade humana (Oliveira \& Albuquerque 2010).

Se na ontologia indígena somos todos humanos, onde habitaria a diferença? Castro (2002, p. 259), responde: "os animais veem da mesma forma que nós coisas diversas do que vemos porque seus corpos são diferentes dos nossos". A diferença encontra-se no corpo, para além das ideias restringentes da fisiologia, mas na abordagem de conjuntos de modos de ser um habitus. O conceito de natureza para os Kaxinawá se aproxima da Grega de physis para o qual "a natureza possui alma, vontade e uma ordem própria, sendo a cultura apenas umas das possibilidades dessa ordem" e o yuxin (espírito) não se entende como ao sobrenatural, mas "como uma força vital permeando todo fenômeno vivo em qualquer parte do mundo". Desse modo, a natureza não está fora do humano e o humano está dentro da natureza. Esta relação não e mecânica, porém orgânica à divindade que se encontra em tudo (Luz, 2002 apud Oliveira \& Albuquerque, 2010, p. 203).

A filosofia ameríndia em sua visão de mundo traz em suas bases a dissolução das oposições entre cultura, natureza, espírito e corpo. Se o espírito permeia os corpos vivos, isto alarga as alteridades a cercar do mundo humano incluindo todos os seres em suas manifestações e configurações naquilo que Viveiros de Castro chama de sabedoria ecosófica. Nas suas palavras: 
os ameríndios não somente passariam ao largo do Grande Divisor cartesiano que separou a humanidade da animalidade, como sua concepção social do cosmo (e cósmica da sociedade) anteciparia as lições fundamentais da ecologia, que apenas agora estamos em condição de assimilar. Antes, ironizava-se a recusa, por parte dos índicos, de conceder os predicados da humanidade a outros homens; agora se sublinha que eles estendem tais predicados muito além das fronteiras da espécie, em uma demonstração de sabedoria "ecosófica" que devemos emular tanto quanto permitam os limites de nosso objetivismo (Castro, 2002, p. 253)

Esse saber ontológico oriundo de comunidade indígena, na perspectiva da filosofia de Dussel e da Interculturalidade filosófica de Fornet-Betancourt, precisa ser considerado no campo filosófico, pois se configura como o respeito ao Outro e aos seus saberes culturais, rompendo com o modelo filosófico eurocêntrico.

Para Dussel a libertação do indígena oprimido, excluído e silenciado se dá na revelação do outro como outro exercendo o seu direto em saber, poder e ser. Isto significa reconhecer, valorizar e legitimar o saber filosófico do indígena, no campo da filosofia. Desta forma, a libertação do oprimido como sujeito pensante e transformador social envolve o reconhecimento do indígena como ser capaz de produzir filosofia além do logos hegemônico europeu.

Na perspectiva da filosofia intercultural o intercambio contextual de filosofias outras, entre as quais a filosofia indígena, ao compartilhar os saberes, enriquece a humanidade.

Assim, compreender a pluralidade do saber filosófico perpassa pelo reconhecimento de diferenças de concepções de mundo e pela legitimação destes saberes no campo das ciências e da filosofia.

As questões que se coloca neste debate e que permanecem para reflexão são: qual o lugar dedicado ao saber ontológico indígena no campo da filosofia?

Se a Filosofia praticada na academia brasileira é de hegemonia eurocêntrica, estaríamos legitimando uma decolonialidade de saber, de ser e de poder em relação aos ameríndios?

E, por fim, existe a possibilidade do diálogo entre os saberes filosóficos? E o diálogo destes saberes na educação indígena?

A possibilidade de existir o diálogo entre os saberes filosóficos pauta-se na compreensão de que os seres humanos filosofam motivados pela curiosidade de conhecer a realidade e solucionar os problemas de seu cotidiano social, com a consciência de que "estamos enraizados em problemas que a condição humana apresenta" (Oliveira, 2006, p. 14).

Assim, como afirma Freire (2004, p.84): "a curiosidade que motiva, que conduz e empurra o conhecimento é a mesma, a do índio, a minha e a tua. Então, não há uma pura curiosidade do índio e da gente". Isto significa que a curiosidade é um ato humano, que possibilita a busca do conhecimento.

Compreendemos que as comunidades indígenas apresentam visões de mundo que precisam ser consideradas no campo filosófico mais geral, sendo estabelecido o diálogo entre os saberes filosóficos, mas para ser efetivado este diálogo, há a necessidade de reconhecimento de que os saberes são plurais e culturais, superando o discurso da universalidade da razão ocidental como única e legítima.

Oliveira \& Albuquerque (2010, p. 209-210) destacam que:

Repensar a filosofia a partir de um olhar intercultural significa romper a visão eurocêntrica em que ela historicamente se assenta e reconhecer uma episteme no saber dos indígenas e de tantos outros grupos que se encontram à margem pensamento ocidental dominante.

Em termos educacionais as autoras defendem que o ensino de filosofia em escolas indígenas deve estabelecer o diálogo entre as filosofias ocidentais clássicas e as filosofias indígenas, reconhecendo a importância destas filosofias para a vida social cotidiana da população indígena, 
quanto para os não indígenas, bem como oportunizando a problematização dos saberes e verdades construídas e estabelecidas de forma hegemônica, estabelecendo tanto uma filosofia quanto uma educação intercultural.

Uma educação escolar indígena intercultural pressupõe, segundo as autoras transformar a educação escolar para os indígenas em educação escolar do indígena, isto é:

implica um outro olhar para estes sujeitos da educação, vendo-os como produtores de conhecimento, de sua história e cultura, além de um outro olhar para a escola, que deixa de ser apenas um espaço de socialização do saber sistematizado dominante para constituir-se como um espaço de diálogo entre culturas e saberes anteriormente dicotomizados (Oliveira \& Albuquerque, 2010, p. 209).

Desta forma, reconhece-se na educação escolar indígena tanto a filosofia quanto os saberes culturais da população indígena. Este reconhecimento perpassa também pela valorização de saberes e filosofia da população indígena, que implica legitimá-los como campo de saber a ser tratado na escola, o que significa mudança curricular e de práticas educativas.

Currículo no qual a presença destes saberes seja constitutiva e práticas dialógicas entre os saberes, sendo a população indígena sujeitos de sua história, cultura e conhecimento.

A educação intercultural na visão de Candau viabiliza o reconhecimento do "outro", estando direcionada para a negociação cultural, porque tanto enfrenta os conflitos provocados pela assimetria de poder entre os grupos socioculturais, quanto pode favorecer a construção de um projeto comum, no qual as diferenças sejam dialeticamente incluídas. Nesta educação a escola torna-se espaço de diálogo, entrecruzamento de culturas e rompe com as práticas educacionais homogeneizadoras (Oliveira, 2015).

\section{CONSIDERAÇÕES FINAIS}

Enrique Dussel e Raúl Betancourt problematizam a hegemonia eurocêntrica na Filosofia e a necessidade de se repensar a ontologia da totalidade além do agir dominador do europeu e suas consequências de marginalização do oprimido e sua nadificação como outro na totalidade, caracterizando-se como um ser-oprimido negado e ontologicamente oculto e colonizado.

Dussel ao colocar em questão a suposta superioridade do paradigma moderno eurocêntrico pelo paradigma mundial como sistema-mundo e omito da modernidade civilizatória dos bárbaros (outros), sendo superado na transmodernidade, no qual o Outro plural, entre os quais, os indígenas, é distinto com igualdades ontológicas, epistemológicas, políticas e culturais.

Crítica a dialética de Heidegger e Hegel como método filosófico que nega e elimina o Outro em ser, tendo como referência o mesmo na totalidade e propõe o método analético como libertação da negação do Outro na totalidade, por meio do qual reconhece e legitima o outro como ser ontológico, epistemológico e cultural.

Para Raúl Betancourt a libertação se dá na abertura do diálogo com o outro sem gerar centro e periferia, mas reconhecendo o Outro como simétrico, horizontal e em situação de igualdade.

Desta forma, o saber filosófico ocidental deve dialogar com o saber filosófico dos indígenas, em uma perspectiva filosófica intercultural, bem como o ensino de filosofia nas escolas indígenas precisam estabelecer o diálogo filosófico na perspectiva de uma educação intercultural.

Contribuições dos Autores: Moraes Júnior, H.: concepção e desenho, aquisição de dados, análise e interpretação dos dados, redação do artigo, revisão crítica relevante do conteúdo intelectual; Oliveira, I. A.: concepção e desenho, aquisição de dados, análise e interpretação dos dados, redação do artigo, revisão crítica relevante do conteúdo intelectual. Todos os autores leram e aprovaram a versão final do manuscrito. 
Aprovação Ética: Não aplicável.

Agradecimentos: Não aplicável.

\section{REFERÊNCIAS}

Betancourt, R. F. (2006). La interculturalidad a prueba. Aachen: Revista Condórdia, 43.

https://studylib.es/doc/8107550/ra\%C3\%BAl-fornet-betancourt-la-interculturalidad-a-prueba

Castro, E. V. de. (2002). A inconsciência da alma selvagem e outros ensaios de antropologia. São Paulo: Cosac Naify.

Dussel, E. (2007). Ética da Libertação na idade da globalização e da exclusão. 3. Ed. Petrópolis, Rio de Janeiro: Vozes.

Dussel, E. (2005). Europa, modernidade e eurocentrismo. In: lander, Edgardo (Org.). A Colonialidade do Saber:

Eurocentrismo e Ciências Sociais perspectivas latino americanas. Colección Sur-Sur. Ciudad Autonoma de Buenos Aires, Argentina: CLACSO.

Dussel, E. (1995). Filosofia da Libertação: critica a ideologia da exclusão. São Paulo: Paulos.

Dussel, E. (1993). 1492, O encobrimento do outro: a origem do mito da modernidade. Petrópolis, Rio de Janeiro: Vozes.

Dussel, E. (1974a). Método para uma Filosofia da Libertação. Editores Loyola: São Paulo.

Dussel, E. (1974b). Método para uma filosofia de la liberación: superación analéctica de la dialética hegeliana. Salamanca: Sígueme.

Hegel, G. W. F. (1992). Fenomenologia do Espírito (parte I). 2. Ed. Petrópolis, Rio de Janeiro: Vozes.

Heidegger, M. (2005). Ser e Tempo (parte I). 15. Ed. Petrópolis, Rio de Janeiro: Vozes.

Jecupé, K. (1998). A terra dos mil povos: história indígena brasileira contado por um índio. São Paulo: Peirópolis.

Oliveira, I. A. O. (2015). Paulo Freire: a gênese da interculturalidade crítica no Brasil. Curitiba: CRV.

Oliveira, I. A., \& Albuquerque, M. B. B. (2010). Filosofia, cultura e educação indígena. In: Henning, L. M. P. (Org.). Pesquisa, ensino e extensão no campo filosófico-educacional: debate contemporâneo sobre a educação filosófica. Londrina: EDUEL, p. 185-213.

Oliveira, I. A. O. (2006). Filosofia da Educação: reflexões e debates. Petrópolis: Vozes.

Freire, P. (2004). Pedagogia da tolerância. São Paulo: UNESP.

Zimmermann, R. (1986). América Latina - O não ser; uma abordagem filosófica a partir de Enrique Dussel (1962-1976). Petrópolis: São Paulo.

Recebido: 2 de abril de 2021 | Aceito: 10 de maio de 2021 | Publicado: 23 de maio de 2021 